Forum $2021 \cdot 36: 260$

https://doi.org/10.1007/s12312-021-00938-9

Online publiziert: 26. April 2021

(c) Springer Medizin Verlag GmbH, ein Teil von Springer Nature 2021

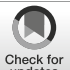

Check for
updates

Die LandesKrebsGesellschaften

EIN NETZ, DAS TRÄGT

Landeskrebsgesellschaften der Deutschen Krebsgesellschaft e.V.

\title{
Landeskrebsgesellschaften sind fit für Social Media
}

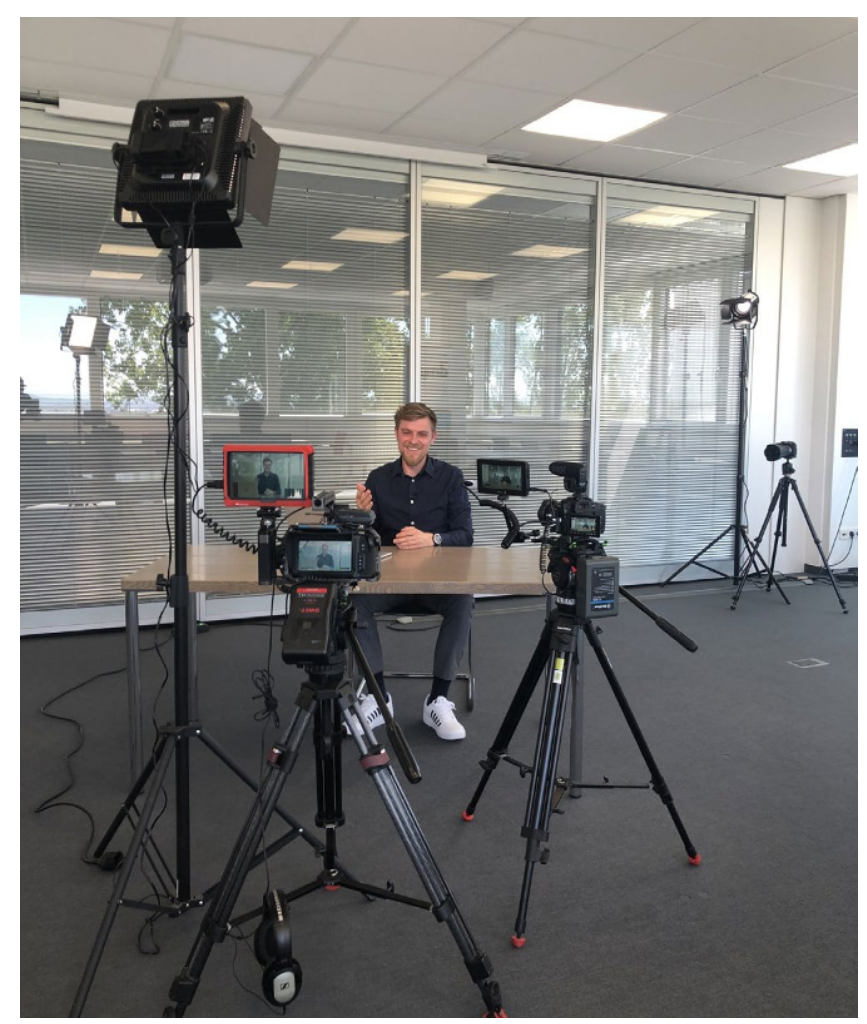

Abb. $1<$ Lars Kroll bei einer Videoaufnahme. (৫) Mit freundlicher Genehmigung Lars Kroll)

ten existieren, wie die Redaktion gelingt und wie Influencer*innen ihnen mit ihrer Reichweite zum Erfolg verhelfen können. „Wir hoffen, dass es uns mit Hilfe von Social Media gelingt, noch mehr Menschen über unsere wichtige Arbeit zu informieren“, sagt Lenkenhoff. „Wenn jemand die schockierende Diagnose Krebs erhält, sind wir als Landeskrebsgesellschaften der erste Ansprechpartner und helfen sofort. Dass das so ist und wie genau unsere Unterstützung aussieht, sollten die Betroffenen auch über die sozialen Netzwerke erfahren“.

\section{Artikel von Carola Pigisch, Journalistin}

\section{Korrespondenzadresse}

\section{Ulrika Gebhardt}

Krebsverband Baden-Württemberg

Adalbert-Stifter-Str. 105,

70437 Stuttgart, Deutschland

info@krebsverband-bw.de 